\title{
Microtubule inhibitor-based antibody-drug conjugates for cancer therapy
}

\author{
This article was published in the following Dove Press journal: \\ OncoTargets and Therapy \\ 3 December 2014 \\ Number of times this article has been viewed
}

\section{Kelsey Klute',* \\ Eleni Nackos ${ }^{1, *}$ \\ Shinsuke Tasaki' \\ Daniel P Nguyen ${ }^{2}$ \\ Neil H Bander ${ }^{2}$ \\ Scott T Tagawa ${ }^{1,2}$}

'Division of Hematology and Medical Oncology, Department of Medicine, Weill Cornell Medical College, New York, NY, USA; '2Department of Urology, Weill Cornell Medical College, New York, NY, USA

*These authors contributed equally to this work
Correspondence: Scott T Tagawa Division of Hematology and Medical Oncology, Department of Medicine, Weill Cornell Medical College, 525 E 68th St, New York, NY 10065, USA Email stt2007@med.cornell.edu

\begin{abstract}
The specificity of monoclonal antibodies represents a potential therapeutic advantage, but their use as single agents in oncology has proven limited to date. The development of antibody-drug conjugates (ADCs) takes advantage of the specificity of the monoclonal antibody and potent cytotoxic effect of chemotherapy, leading to enhanced cytotoxicity in target cells and limiting toxicity to normal tissue. Microtubules represent a validated oncologic target in a range of tumor types, with a number of anti-microtubule targeting cytotoxic drugs approved for cancer use. The systemic use of potent microtubule-binding agents is limited by their effects in normal cells, which leads to toxicity including myelosuppression and peripheral neuropathy. Linking these agents to monoclonal antibodies may limit toxicity to normal tissues and increase drug concentration in target tissues, also allowing the use of more potent agents which would be too toxic to administer in their unbound form. Two such ADCs have been approved for clinical use and many others are in development. Here we review the characteristics of each of the ADC components that have led to efficacious therapies and discuss some of the tubulin inhibitor-based ADCs in development for cancer therapy.
\end{abstract}

Keywords: monoclonal antibody, antibody-drug conjugate, microtubule inhibitor

\section{Introduction}

In the past decade, more than ten monoclonal antibodies (mAbs) have been approved for use in the treatment of cancer (Table 1). Their specificity and favorable side effect profile make them attractive; however, their activity as monotherapy may be limited. Despite the development of mAbs and small molecule pathway inhibitors, cytotoxic chemotherapy remains the foundation for cancer treatment. Microtubules (MTs) are one of the most validated intracellular targets in oncology, though because of their ubiquitous presence and importance in all cells, generic delivery of anti-MT agents with chemotherapy has "off-target" toxicity. The development of antibody-drug conjugates (ADCs) takes advantage of the specificity of the mAb while augmenting its ability to produce a cytotoxic effect. A number of new anti-MT agents remain attractive options for antibody conjugation in light of their intracellular mechanism of action and relatively potent degree of cytotoxicity. The primary benefits of antibody-drug conjugation are enhancement of cytotoxicity in target cells and limiting toxicities of cytotoxic drugs in normal tissues. The simplicity of this paradigm is attractive; however, the development of ADCs that are effective in clinical use has proven to be quite complex.

The earliest ADCs combined drugs that were already approved for clinical use. These drugs were readily available, and their efficacies and toxicities were well understood. One of the earliest ADCs, BR96-doxorubicin, was a chimeric anti-Lewis-Y mAb conjugated to doxorubicin that was studied in patients with metastatic colon and breast 
Table I Monoclonal antibodies and antibody conjugates approved by the US Food and Drug Administration for use in cancer treatment

\begin{tabular}{|c|c|c|c|}
\hline $\begin{array}{l}\text { Generic } \\
\text { name }\end{array}$ & Description & Target & $\begin{array}{l}\text { Approval } \\
\text { date }\end{array}$ \\
\hline Rituximab & Chimeric IgGI & CD20 & 1997 \\
\hline Trastuzumab & Humanized lgG4 & HER2 & 1998 \\
\hline $\begin{array}{l}\text { Gemtuzumab } \\
\text { ozogamicin }\end{array}$ & Humanized IgGI & $\begin{array}{l}\text { CD33 } \\
\text { (immunotoxin) }\end{array}$ & 2000 \\
\hline Alemtuzumab & Humanized IgGI & CD52 & 2001 \\
\hline Ibritumomab tiuxetan & Murine $\mid g G I$ & $\begin{array}{l}\text { CD20 } \\
\text { (radiolabeled) }\end{array}$ & 2002 \\
\hline${ }^{|3|} \mid$-Tositumomab & Murine $\operatorname{lgG} 2$ & $\begin{array}{l}\text { CD20 } \\
\text { (radiolabeled) }\end{array}$ & 2003 \\
\hline Cetuximab & Chimeric IgGI & EGFR & 2004 \\
\hline Bevacizumab & Humanized lgGI & VEGF & 2004 \\
\hline Panitumumab & Human $\operatorname{lgG} 2$ & EGFR & 2006 \\
\hline Ofatumumab & Human IgGI & CD20 & 2009 \\
\hline Ipilimumab & Human IgGI & CTLA-4 & 2011 \\
\hline Denosumab & Human IgG2 & RANK ligand & 2010 \\
\hline Brentuximab vedotin & Chimeric IgGI & CD30 & 2011 \\
\hline Pertuzumab & Human $\operatorname{lgGI}$ & HER2 & 2012 \\
\hline Obintuzumab & $\begin{array}{l}\text { Humanized and } \\
\text { glycoengineered }\end{array}$ & $\mathrm{CD} 20$ & 2013 \\
\hline $\begin{array}{l}\text { Trastuzumab } \\
\text { emtansine }\end{array}$ & Humanized IgG4 & $\begin{array}{l}\text { HER2 } \\
\text { (mertansine) }\end{array}$ & 2013 \\
\hline Ramucirumab & Human IgGI & VEGFR2 & 2014 \\
\hline
\end{tabular}

Abbreviations: Ig, immunoglobulin; EGFR, epidermal growth factor receptor; VEGF, vascular endothelial growth factor; VEGFR, vascular endothelial growth factor receptor; CTLA, cytotoxic T-lymphocyte-associated protein.

cancer. ${ }^{1}$ However, due to a combination of broad expression of the target antigen with relative low potency of the drug, the ADC did not move forward to late-stage trials for approval. ${ }^{2}$

Here we review the characteristics of each of the ADC components that have led to efficacious therapies, and discuss some of the tubulin inhibitor-based ADCs in development for cancer therapy.

\section{Rationale for targeted anti-MT therapy}

MT-binding agents are widely used in cancer chemotherapy as both monotherapy and combination therapy. MTs play a key role in mitosis, intracellular trafficking, and motility and are a major therapeutic target in cancer. Based on the pivotal role of the MT dynamics on mitosis, ${ }^{3}$ extensive research identified mitosis as a classic target of MT-binding agents. MT-binding agents are classified as MT stabilizers or destabilizers. Both stabilizers and destabilizers inhibit cell proliferation at clinically relevant low concentrations by suppressing MT dynamics and interfering with normal MT functions during both the interphase and mitotic stages of the cell cycle. ${ }^{4}$ MT-organizing centers represent the structures from which mitotic spindles emanate, generated from two centrosomes (spindle poles). The centrosomes serve as two opposing poles for spindle MTs during cell division. MTs form this mitotic spindle crucial for separation during mitosis; thus, MT inhibitors consequently have a role in mitotic arrest by interrupting MTs and the dependent movement of chromosomes. However, it is unlikely that mitosis is the primary target of MT-binding agents in humans, as the doubling time of most solid tumor cells is low. ${ }^{5}$

MTs are very important for the directional intracellular transport of vesicles, proteins, and messenger ribonucleic acid. ${ }^{6}$ Immunohistochemistry images demonstrated that many crucial oncoproteins were associated with MTs. p53 protein localizes to cellular MTs, and treatment with vincristine or paclitaxel reduces nuclear accumulation of $\mathrm{p} 53 .{ }^{7} \mathrm{Rb}$ together with p53 and PTHrP requires intact MTs for efficient nuclear import. ${ }^{8}$ Paclitaxel impairs HIF- $1 \alpha$ protein nuclear translocation, which downregulates HIF transcriptional activity. ${ }^{9}$ A recently described practical example of a validated target trafficked by MTs is the androgen receptor (AR) in prostate cancer. The AR has been shown to be vital to prostate cancer progression throughout its life cycle, despite the emergence of resistance to castration. To date, taxanes are the only cytotoxic chemotherapy agents that have been shown to prolong survival among men with prostate cancer. ${ }^{10,11}$ The AR requires nuclear translocation on MT-dynein-dependent intracellular trafficking. Taxanes inhibit ligand-induced AR nuclear translocation and downstream transcriptional activation of prostatespecific antigen, which is an AR target gene. ${ }^{12}$ Experiments identified intracellular trafficking by MTs in nondividing cells on interphase as a new important target of MT-binding agents. MT-binding agents have a cytotoxic effect not only on dividing cells in mitosis but also on nondividing cells in interphase. ${ }^{5}$

MTs also serve important roles in cytoskeleton formation, endothelial cell adhesion, migration, and cell-to-cell interaction, thus providing additional targets to disrupt cellular function through the action of MT-binding agents. Tumor angiogenesis requires proliferation and migration of endothelial cells. Recent studies reveal antivascular effects of MT-binding agents in vivo and in vitro. ${ }^{13}$ Combretastatin A4 phosphate increases endothelial cell permeability and inhibits endothelial cell migration and capillary tube formation thorough disruption of the VE-cadherin/ $\beta$-catenin/Akt signaling pathway. ${ }^{14}$ Combretastatin A4 phosphate induces a reduction in tumor blood flow in a different way from nitric oxide synthase inhibition. ${ }^{15}$

\section{Toxicity of MT-binding agents}

Hematologic toxicity and peripheral neuropathy are the major dose-limiting toxicity of MT-binding agents. Myelosuppression, due to disruption of mitotic phase MT function in the 
bone marrow, often manifests as neutropenia, since leukocyte precursors in the marrow are actively undergoing mitosis. The therapeutic target of taxanes, vinca alkaloids, and epothilones is $\beta$-tubulin, which consists of eight isotypes. $\beta$-tubulin isotype VI is hematopoietic cell-specific and detected in platelets and lymphocytes in bone marrow and is highly expressed in blood cells with substantial interindividual variability. Patients with a $\beta$-tubulin VI variant exhibited significantly less thrombocytopenia than wild-type homozygous patients when treated with paclitaxel. ${ }^{16}$ Peripheral neuropathy is frequently observed with anti-MT agents and represents the disruption of interphase MT function, since neuronal cells rarely divide in adults. The mechanisms causing peripheral neuropathy have not been clarified. However, axonal transport is an essential process in neurons, and MTs in the axon essentially form tracks along which various cargoes can be transported by various motor proteins. ${ }^{17} \beta$-tubulin isotype IIa forms part of the neuronal MTs as a therapeutic target of paclitaxel in neurons. A large interindividual variability in the expression of $\beta$-tubulin IIa and an association between paclitaxel-induced peripheral neuropathy and regulatory polymorphisms in $\beta$-tubulin IIa have been reported. ${ }^{16}$ These dose-limiting toxicities are due to a noncancer-specific targeting capacity of drug, since MTs play pivotal roles not only in cancer cells but also in normal cells.

In addition to some of the approved anti-MT drugs discussed here, more potent drugs underwent initial clinical development; however, they were too toxic for untargeted use. With the advent of technology to more precisely deliver these potent drugs to their target, they are quite appealing for use in ADCs. One such group of drugs is the maytansinoids tubulin-binding agents with cytotoxic effects almost 100 -fold higher than vinca alkaloids. ${ }^{18}$ Currently, the vast majority of the 29 ADCs in clinical trials employ either maytansinoids or auristatins as drug payload. Since drug delivery to tumor cells is limited by antigen copy number on tumor cells, cytotoxicity at low concentration is crucial. It is estimated that in order to achieve a clinically relevant degree of cytotoxicity, a drug used in an ADC must be at a half maximal inhibitory concentration $\left(\mathrm{IC}_{50}\right)$ level of at least $10-100 \mathrm{pM}$. The in vitro cytotoxicity $\left(\mathrm{IC}_{50}\right.$ value) of the maytansinoids is even lower than this suggested level, which is why mertansine (DM1) is the most commonly used agent in ADC development. ${ }^{19}$

Additionally, maytansinoids remain nontoxic in their conjugated form. This prevents decomposition before delivery to the target site, which both limits toxic effects on normal tissues and maximizes the amount of drug that reaches the target site.

\section{Antibody and antigen characteristics}

One of the problems with BR96-doxorubicin was its lack of specific expression in tumor cells. In a Phase II trial, patients in the BR96-doxorubicin conjugate group had limited hematologic toxicities compared with the single-agent doxorubicin group; however, the group treated with the ADC had marked gastrointestinal toxicity, suggesting that the target antigen, Lewis-Y, was expressed in the gastrointestinal tract. It is postulated that this not only led to increased toxicity but also limited delivery to target tissues. ${ }^{2}$

Design of an ADC relies on the proper selection of a tumor-specific antigen that is accessible for antibody binding and subsequent delivery of the ADC to its pharmacologic target. The basis behind ADCs lies in the specificity of antigen expression by tumor cells, which permits drug delivery to target tissues with relative sparing of healthy tissues. Likewise, the level of expression of the target antigen on tumor cells determines drug delivery as well as effect on normal tissues. If a target antigen is not expressed at high levels on tumor cells, ADC uptake will be low, which will limit cytotoxicity and may lead to accumulation of drug extracellularly and nonspecific toxicity to normal cells. ${ }^{20}$

Since MT agents act intracellularly, it is crucial that the target antigen transports the ADC intracellularly. If the antigen does not internalize, drug will not reach adequate concentration to cause cytotoxicity, and ADC may diffuse away and expose normal cells to toxic effects. ${ }^{20}$

It is also crucial that the antigen be expressed homogeneous in tumor cells. Intratumoral homogeneity of the target antigen allows ADC to reach more of the tumor. Tumor cells not expressing the target antigen will not bind and internalize the ADC, and will only derive cytotoxic effect by nonspecific mechanisms. Additionally, the target antigen must be easily accessible from the bloodstream. ${ }^{20}$

\section{Linker characteristics}

One fundamental aspect in the development of ADCs with regard to potency and tolerability has been the generation of stable linkers that connect the drug to the mAb. ADC processing generally follows sequential steps: binding to the cell surface target antigen, internalization into an endosome, trafficking to a lysosome, release of the drug, and diffusion of the cytotoxic agent to its site of action. ${ }^{18}$ The ideal linker must be stable in the systemic circulation to avoid off-target toxicity yet allow efficient drug release within the target site where it can reach its intracellular target.

Most linkers fall into two categories: cleavable and noncleavable. Cleavable linkers contain sites for hydrolytic or 
enzymatic cleavage in the endosome/lysosome allowing ready separation of the drug and its diffusion to the site of action. In addition, by allowing the released drug to also diffuse back outside the cell, cleavable linkers allow bystander killing of nontargeted antigen-negative tumor cells, ${ }^{18,21}$ a particular advantage in the case of a heterogeneously expressed target antigen. Noncleavable linkers require proteolytic degradation of the antibody portion of the ADC within the lysosome in order to release the cytotoxic molecule. In this case, the drug is released along with its charged lysine or cysteine amino acid through which the drug was attached to the antibody. ${ }^{22,23}$ The charged amino acid, in turn, prevents diffusion of the charged drug back through the cell membrane, thereby leading to drug accumulation within the tumor cell but also precluding a bystander effect. Noncleavable linkers hold the advantage of minimizing drug release in the circulation; however, they require highly efficient internalization into the cell and homogeneous expression of the target antigen by the tumor cell population.

Early generation cleavable linkers included unhindered disulfides and acid-labile hydrazones. ${ }^{24,25}$ Disulfide-based linkers are cleaved following thiol-disulfide exchange reactions, while acid-labile hydrazones undergo hydrolysis in the acidic endosomes and lysosomes upon ADC internalization. ${ }^{26}$ Unfortunately, these linkers were relatively labile, and cleavage frequently occurred in the circulation, resulting in both off-target toxicity and attenuated antitumor activity as the payload had been jettisoned prior to tumor uptake. ${ }^{27}$ Subsequent development of sterically hindered disulfide bonds using methyl substitutions improved ADC stability and thus tolerability and potency. ${ }^{28}$ These advances were later incorporated into mAb-maytansinoid conjugates. ${ }^{18}$ Currently, many of the linkers that have entered clinical trials are disulfide-based, including IMGN901 (lorvotuzumab mertansine) targeting CD56 and SAR3419 targeting CD19 as just two examples. ${ }^{29,30}$ Another type of cleavable linkers are dipeptides, the development of which was a major advance in the development of US Food and Drug Administration (FDA)-approved brentuximab vedotin (anti-CD30-monomethylauristatin E [MMAE]). ${ }^{27,31}$ These linkers are composed of a valine-citrulline dipeptide that is degraded by lysosomal proteases such as cathepsin B. ${ }^{32}$ This technology has subsequently been applied to prostatespecific membrane antigen (PSMA) mAb-MMAE conjugate and CDX-011 (glembatumumab vedotin), among many others. ${ }^{33-35}$ Recently, it has been demonstrated that manipulation of the C-terminal peptide sequence of these linkers can increase the potency and specificity of auristatins, thus improving the therapeutic window. ${ }^{36}$
The most commonly used noncleavable linkers are thioether bonds. Thioether linkers have been used to link the auristatin monomethyl auristatin $\mathrm{F}$ to $\mathrm{mAbs}$. In vivo experiments showed equal efficacy and better tolerability compared with the corresponding ADC linked by the cleavable dipeptide linkers. ${ }^{27}$ This methodology has also been applied to maytansinoids. Thioether-linked huC242 mAb-maytansinoid conjugates had comparable in vitro potency with the corresponding disulfide-linked ADCs; however, they displayed less activity in vivo, ${ }^{21,37}$ presumably due to lack of the bystander effect. Conversely, the only FDA-approved mAb-maytansinoid conjugate to date, trastuzumab emtansine, an HER2-targeting $\mathrm{mAb}$ conjugated to DM1, has enhanced activity with thioether linkers in comparison with disulfide linkers. ${ }^{38}$ These findings suggest that the biology of the target antigen and the biology of the tumor may influence activity of $\mathrm{mAb}$-drug conjugates. In this regard, caution is warranted, as in vitro efficacies of ADCs do not always predict in vivo potencies. ${ }^{18}$

In addition to disulfide-, peptide-, and thioether-based linkers, sulfonate- or polyethylene glycol-containing hydrophilic linkers for mAb-maytansinoid conjugates have recently emerged. This new class of linkers allows a higher drug/antibody ratio while increasing toxicity for antigenpositive cells and decreasing cytotoxicity for antigen-negative cells.

The linker component is critical in the design of ADCs. There is no single "perfect" linker, due to variations in ADC processing from tumor type to tumor type and from target antigen to target antigen. For any $\mathrm{mAb}$-drug conjugate, the optimal linker for a particular application currently needs to be determined empirically.

\section{Approved ADCs}

There are currently two FDA-approved ADCs - trastuzumab emtansine and brentuximab vedotin - both humanized antibodies conjugated to anti-MT agents. The approval of these two agents followed the withdrawal of the only other approved ADC, gemtuzumab ozogamicin, in 2010. ${ }^{39}$ Gemtuzumab ozogamicin received accelerated approval as monotherapy for acute myeloid leukemia in patients aged $>60$ years. Its approval was based on the results of a Phase II study showing promising results, ${ }^{40}$ but gemtuzumab ozogamicin failed to show efficacy and demonstrated excessive toxicity in a randomized study by the Southwest Oncology Group in 2010 and was subsequently voluntarily withdrawn from the market. ${ }^{41}$

Trastuzumab emtansine is an HER2 ADC that comprises a trastuzumab antibody linked to a tubulin polymerization inhibitor, mertansine (a maytansine derivative; also known 
as DM1), and was launched as second-line monotherapy for relapsed HER2-positive metastatic breast cancer in February of 2013. ${ }^{42}$ Brentuximab vedotin, an ADC composed of an anti-CD30 antibody linked to MMAE, an anti-MT agent, was approved for the treatment of refractory Hodgkin lymphoma in August of 2011, for the treatment of patients with refractory Hodgkin lymphoma and systemic anaplastic large-cell lymphoma. ${ }^{43}$

\section{Trastuzumab emtansine}

Trastuzumab emtansine (T-DM1) is an ADC approved for use in treatment of HER2 overexpressed breast cancer. Its antibody component, trastuzumab, is a humanized $\mathrm{mAb}$ that targets the extracellular domain of the HER2 receptor and has been in widespread use since its initial approval in $1998 .{ }^{44}$ It is linked using a nonreducible thioether bond to DM1. Trastuzumab is well known to be clinically efficacious in combination with taxane-based chemotherapy, ${ }^{45}$ and in preclinical models, trastuzumab enhanced antitumor activity in a paclitaxel-based regimen. ${ }^{46}$ Therefore, trastuzumab linked to an MT-targeted drug was an appealing model for ADC development.

HER2 is a transmembrane receptor protein that plays an important role in cell differentiation, proliferation, and survival. It is expressed at relatively low levels in normal adult tissues ${ }^{47}$ but is overexpressed by $20 \%-30 \%$ of breast tumors. ${ }^{48}$ Expression of HER2 on the surface of involved breast cancer cells can be as dense as 1.5 million copies per cell. ${ }^{49}$ HER 2 expression in breast cancer is generally homogeneous, with only $5 \%-15 \%$ of tumors having heterogeneous expression. ${ }^{50,51}$ After binding, the T-DM1-HER2 complex is endocytosed and degraded in lysosomes. ${ }^{52}$

A Phase I open-label dose-escalation study evaluated the safety and tolerability of T-DM1 in 24 patients with HER2-positive metastatic breast cancer who had previously progressed on trastuzumab-based therapy. ${ }^{53}$ Following an initial safety cohort of three patients treated at $0.3 \mathrm{mg} / \mathrm{kg}$, single-subject dose escalation $(0.6,1.2$, and $2.4 \mathrm{mg} / \mathrm{kg})$ proceeded without grade 2 toxicity until $4.8 \mathrm{mg} / \mathrm{kg}$ was reached with cohort expansion. At this dose, two of three patients experienced grade 4 thrombocytopenia. Therefore, six patients were treated at an intermediate dose level (3.6 mg/ $\mathrm{kg}$ ) without any dose-limiting toxicity, leading to the conclusion that $3.6 \mathrm{mg} / \mathrm{kg}$ was the maximum tolerated dose (MTD). This cohort was expanded to a cohort of 15 patients, five of whom experienced objective partial response. Of the total 24 patients in the study, six patients had an objective partial response, five of which occurred at the MTD. Clinical benefit rate (objective response + stable disease at 6 months) at the MTD was 73\%, and cardiac toxicities were not observed.

On the basis of its efficacy and safety profile, T-DM1 entered Phase III studies. The pivotal study, termed the EMILIA trial, compared the use of T-DM1 with capecitabine plus lapatinib in 991 women with metastatic HER2 overexpressed breast cancer who had previously received a taxane and trastuzumab. ${ }^{54}$ T-DM1 significantly prolonged progression-free survival (9.6 vs 6.4 months; stratified hazard ratio of $0.65 ; 95 \%$ confidence interval, $0.55-0.77$ ) and overall survival (30.9 months vs 25.1 months; stratified hazard ratio of 0.68 ; $95 \%$ confidence interval, $0.55-0.85$ ), with less toxicity than lapatinib plus capecitabine. On the basis of these results, T-DM1 was approved by the FDA in February 2013 for use in HER2 overexpressing breast cancer that had progressed on prior trastuzumab and taxane therapy. ${ }^{54}$ This represented the first ADC to be approved for use in solid tumors and was a significant advance in the treatment of HER2 overexpressing metastatic breast cancer.

Several ongoing trials will further define the use of T-DM1. T-DM1 is being evaluated in the MARIANNE trial for use in the frontline metastatic setting in a large Phase III trial comparing T-DM1 and pertuzumab with trastuzumab and a taxane in patients with untreated metastatic or recurrent breast cancer. ${ }^{55,56}$ TH3RESA, another Phase III trial, is comparing T-DM1 with physician's choice of therapy after at least two prior regimens of HER2-targeted therapy. ${ }^{57}$ T-DM1 is also being evaluated in both the adjuvant ${ }^{58-60}$ and neoadjuvant ${ }^{61}$ breast cancer settings. T-DM1 combinations are of interest, including T-DM1 in combination with cytotoxic chemotherapy, ${ }^{62,63}$ as well as an interesting study combining T-DM1 with pertuzumab. ${ }^{64}$ Additional work is also proceeding in other tumor types. Based upon efficacy in preclinical models of HER2-positive gastric cancer, ${ }^{65}$ it is being compared with taxane in an ongoing Phase II/III study in patients with advanced HER2-positive advanced gastric cancer. ${ }^{66}$

\section{Brentuximab vedotin}

Brentuximab vedotin is a CD30-directed ADC approved for relapsed/refractory Hodgkin lymphoma and anaplastic large-cell lymphoma. Brentuximab vedotin (SGN-35) is composed of the chimeric anti-CD30 mAb cAC10 conjugated by a protease-cleavable linker to four molecules of MMAE. CD30 is a member of the tumor necrosis factor receptor superfamily. In nonpathologic conditions, CD30 expression is found in activated T- and B-lymphocytes, natural killer cells, and Epstein-Barr virus-infected cells. ${ }^{67} \mathrm{CD} 30$ is uniformly 
expressed in Hodgkin lymphoma and anaplastic large-cell lymphoma, and is less consistently expressed in a number of other lymphomas. ${ }^{68}$ Despite their limited expression, anti-CD30 antibodies showed minimal clinical activity in CD30-positive malignancies. ${ }^{69,70}$

Brentuximab vedotin was shown to be highly effective, selective for CD30-positive tumor cells, and highly potent $\left(\mathrm{IC}_{50}<10 \mathrm{ng} / \mathrm{mL}\right)$ in preclinical studies. ${ }^{31,71}$ In Phase I studies it was tolerable, did not reach MTD, and showed evidence of clinical activity in Hodgkin lymphoma and anaplastic large-cell lymphoma but not peripheral T-cell lymphoma. ${ }^{72,73}$ Phase II studies used $1.8 \mathrm{mg} / \mathrm{kg}$ brentuximab vedotin every 3 weeks in patients with Hodgkin lymphoma who had relapsed after autologous stem cell transplant ${ }^{74}$ and in patients with relapsed or refractory anaplastic large-cell lymphoma. ${ }^{75}$ Overall response rates were $75 \%$ and $88 \%$, respectively. Brentuximab vedotin was given accelerated FDA approval in 2011 based on the results of these trials. It is approved for use in patients with Hodgkin lymphoma who have relapsed or have refractory disease after autologous stem cell transplant or two prior multiagent chemotherapy regimens, and for patients with systemic anaplastic large-cell lymphoma in the second-line setting. ${ }^{43}$

Brentuximab vedotin has also been shown to have activity as a bridge to allogeneic stem cell transplantation ${ }^{76}$ and in relapsed Hodgkin lymphoma after allogeneic stem cell transplantation. ${ }^{77}$ Several ongoing trials will evaluate the role of brentuximab vedotin patients with high risk of residual disease following autologous stem cell transplantation ${ }^{78}$ as first-line monotherapy therapy and in combination with doxorubicin, vinblastine, and dacarbazine. ${ }^{79}$

\section{Example of ADCs in clinical trials: PSMA}

While the approved ADCs clearly allow delivery of cytotoxic drugs preferentially to tumor cells with a proven favorable risk:benefit ratio, neither HER2 nor CD30 are tumor-specific. One example of a tumor-restricted, highly expressed antigen is PSMA. In contrast to prostate-specific antigen, which is a secreted protein, PSMA is an integral cell-surface membrane protein. Expression is highly restricted and the limited expression on the luminal surface of normal prostate epithelium is not thought to be a clinical issue, as the prostate is a nonessential organ. ${ }^{80}$ Initially thought to be present only in prostate and prostate cancer tissue, low levels of expression were subsequently found in renal proximal tubules, astrocytes, and Schwann cells, and more weakly by the small bowel. ${ }^{80}$ Levels of PSMA in prostate tissue are 10- to 100-fold higher than those in membrane from extraprostatic tissues, and sites of expression are not typically accessible to circulating full-length mAb. ${ }^{80,81}$ PSMA expression is detected on approximately $90 \%$ of prostate tumors. ${ }^{80-83}$ Of particular relevance in the modern era of highly potent AR-targeted therapy, PSMA expression increases with AR dysregulation. ${ }^{83-85}$ Interestingly, PSMA expression on the neovasculature of approximately $85 \%$ of solid tumors, but not normal vasculature, makes PSMA an attractive target in other solid tumors as well. ${ }^{86,87}$

The initial anti-PSMA mAb 7E11 (capromab), though approved for clinical use as an imaging agent conjugated to indium-111, has been of limited clinical use based upon its recognition of an intracellular epitome on PSMA, leading to an inability to bind viable prostate cancer cells. The subsequent development of mAbs against the external domain of PSMA has been more successful in targeting tumors. ${ }^{87}$ The J591 mAb has demonstrated accurate tumor targeting as well as antitumor efficacy when radiolabeled with beta-emitting radionuclides. ${ }^{88-92}$ As discussed, PSMA is an ideal target of ADCs based upon its specificity and high level of expression. The existence of fairly readily available PSMA antibodybased imaging also allows for in vivo assessment of tumor antigen assessment as well as drug distribution. ${ }^{92}$ The initial anti-PSMA ADC to complete Phase I and II studies utilized J591 and maytensinoid-1 conjugated with a thiopentanoate linker. ${ }^{93-95}$ Despite known specific tumor targeting with this $\mathrm{mAb}$, the disulfide linker lability using older technology led to rapid deconjugation to free DM1 and a narrow therapeutic window with significant neurotoxicity. ${ }^{95}$ More recently, another $\mathrm{mAb}$ against the external domain of PSMA linked via a more stable thioether bond has completed Phase II studies with encouraging results. ${ }^{33}$ Based upon the tumor-restricted expression of PSMA with increasing levels of expression seen with modern AR-targeted therapy, and the clinically proven sensitivity of prostate cancer to MT-targeted agents, additional anti-PSMA ADCs are in development.

\section{Summary}

ADCs have made significant progress in the treatment of Hodgkin lymphoma, anaplastic large-cell lymphoma, and metastatic breast cancer. MTs remain one of the most validated targets in oncology, and by utilizing the specificity of mAbs, anti-MT ADCs may be able to deliver a highly cytotoxic payload to selected tumor cells. A number of anti-MTbased ADCs are currently undergoing active clinical trials (Table 2), and even more are in preclinical development. The ADC model, appealing for its specificity and limited toxicity, has historically proven to be a complex challenge in drug development. However, development of tumor-restricted 
Table 2 Antibody-drug conjugates (ADCs) in humans

\begin{tabular}{|c|c|c|c|c|}
\hline$\overline{A D C}$ & Company & Target & Tumor & Phase \\
\hline Trastuzumab-emtansine (T-DMI) & Genentech & HER2 & Breast & Approved \\
\hline \multirow[t]{2}{*}{ Brentuximab vedotin } & Seattle & CD30 & Hodgkin lymphoma, anaplastic & Approved \\
\hline & Genetics & & large-cell lymphoma & \\
\hline CDX-0II & Celldex & Glycoprotein & Breast (TNBC), melanoma & Phase I, II \\
\hline Glembatumumab vedotin & & NMB (GNMB) & & \\
\hline IMGN90I & Immunogen & CD56 & MM, SCLC, MCC & Phase I, II \\
\hline \multicolumn{5}{|l|}{ Lorvotuzumab mertansine } \\
\hline PSMA-ADC & Progenics & PSMA & Prostate cancer & Phase II \\
\hline SAR34I9 & Sanofi & CDI9 & DLBCL, follicular lymphoma & Phase II \\
\hline ABT-4I4 & AbbVie & EGFR & Solid tumors & Phase II \\
\hline RG-7596/DCDS450IA & Roche & CD79b & DLBCL, non-Hodgkin lymphoma & Phase II \\
\hline \multicolumn{5}{|l|}{ Polatuzumab vedotin } \\
\hline RG-7593/DCDT2980S & Roche & CD22 & DLBCL, non-Hodgkin lymphoma & Phase II \\
\hline \multicolumn{5}{|l|}{ Pinatuzumab vedotin } \\
\hline Gemtuzumab ozogamicin & Wyeth & CD33 & AML & Approved, withdrawn \\
\hline
\end{tabular}

Abbreviations: TNBC, triple negative breast cancer; MM, multiple myeloma; SCLC, small-cell lung cancer; MCC, Merkel cell cancer; PSMA, prostate-specific membrane antigen; DLBCL, diffuse large B-cell lymphoma; EGFR, epidermal growth factor receptor; AML, acute myeloid leukemia.

mAbs plus improved linker technology has led to clinical advancement. The success of ADCs in development will be driven by selection of targets that limit drug exposure to healthy tissues and thoughtful selection of each of the ADC components. In the effort to kill cancer cells while sparing patients from toxicities, ADCs remain a promising and novel approach to cancer therapy.

\section{Disclosure}

Neil H Bander is an inventor on patents that are assigned to the Cornell Research Foundation (CRF) for the J591 antibody described in this article. Dr Bander is a paid consultant to, and owns stock in, BZL Biologics, the company to which the patents were licensed by CRF for further research and development. He also serves as chair of ADC Therapeutics Scientific Advisory Board. Scott T Tagawa has received research funding from Progenics. The other authors report no conflicts of interest in this work.

\section{References}

1. Saleh MN, Sugarman S, Murray J, et al. Phase I trial of the anti-lewis $\mathrm{Y}$ drug immunoconjugate BR96-doxorubicin in patients with lewis Y-expressing epithelial tumors. J Clin Oncol. 2000;18(11):2282-2292.

2. Tolcher AW, Sugarman S, Gelmon KA, et al. Randomized phase II study of BR96-doxorubicin conjugate in patients with metastatic breast cancer. J Clin Oncol. 1999;17(2):478-484.

3. Hall A. The cytoskeleton and cancer. Cancer Metastasis Rev. 2009; 28(1-2):5-14.

4. Dumontet C, Jordan MA. Microtubule-binding agents: a dynamic field of cancer therapeutics. Nat Rev Drug Discov. 2010;9(10):790-803.

5. Komlodi-Pasztor E, Sackett D, Wilkerson J, Fojo T. Mitosis is not a key target of microtubule agents in patient tumors. Nat Rev Clin Oncol. 2011;8(4):244-250.

6. Verhey KJ, Hammond JW. Traffic control: regulation of kinesin motors. Nat Rev Mol Cell Biol. 2009;10(11):765-777.
7. Giannakakou P, Sackett DL, Ward Y, Webster KR, Blagosklonny MV, Fojo T. P53 is associated with cellular microtubules and is transported to the nucleus by dynein. Nat Cell Biol. 2000;2(10):709-717.

8. Roth DM, Moseley GW, Glover D, Pouton CW, Jans DA. A microtubulefacilitated nuclear import pathway for cancer regulatory proteins. Traffic. 2007;8(6):673-686.

9. Carbonaro M, Escuin D, O’Brate A, Thadani-Mulero M, Giannakakou P Microtubules regulate hypoxia-inducible factor-1alpha protein trafficking and activity: implications for taxane therapy. J Biol Chem. 2012;287(15):11859-11869.

10. Tannock IF, de Wit R, Berry WR, et al. Docetaxel plus prednisone or mitoxantrone plus prednisone for advanced prostate cancer. $N$ Engl J Med. 2004;351(15):1502-1512.

11. de Bono JS, Oudard S, Ozguroglu M, et al. Prednisone plus cabazitaxel or mitoxantrone for metastatic castration-resistant prostate cancer progressing after docetaxel treatment: a randomised open-label trial. Lancet. 2010;376(9747):1147-1154.

12. Thadani-Mulero M, Nanus DM, Giannakakou P. Androgen receptor on the move: boarding the microtubule expressway to the nucleus. Cancer Res. 2012;72(18):4611-4615.

13. Schwartz EL. Antivascular actions of microtubule-binding drugs. Clin Cancer Res. 2009;15(8):2594-2601.

14. Vincent L, Kermani P, Young LM, et al. Combretastatin A4 phosphate induces rapid regression of tumor neovessels and growth through interference with vascular endothelial-cadherin signaling. J Clin Invest. 2005;115(11):2992-3006.

15. Tozer GM, Prise VE, Wilson J, et al. Mechanisms associated with tumor vascular shut-down induced by combretastatin A-4 phosphate: intravital microscopy and measurement of vascular permeability. Cancer Res. 2001;61(17):6413-6422.

16. Leandro-Garcia LJ, Leskela S, Jara C, et al. Regulatory polymorphisms in beta-tubulin IIa are associated with paclitaxel-induced peripheral neuropathy. Clin Cancer Res. 2012;18(16):4441-4448.

17. Millecamps S, Julien JP. Axonal transport deficits and neurodegenerative diseases. Nat Rev Neurosci. 2013;14(3):161-176.

18. Erickson HK, Park PU, Widdison WC, et al. Antibody-maytansinoid conjugates are activated in targeted cancer cells by lysosomal degradation and linker-dependent intracellular processing. Cancer Res. 2006;66(8):4426-4433.

19. Lambert JM. Drug-conjugated antibodies for the treatment of cancer. Br J Clin Pharmacol. 2013;76(2):248-262.

20. Bander NH. Antibody-drug conjugate target selection: critical factors. Methods Mol Biol. 2013;1045:29-40. 
21. Kovtun YV, Audette CA, Ye Y, et al. Antibody-drug conjugates designed to eradicate tumors with homogeneous and heterogeneous expression of the target antigen. Cancer Res. 2006;66(6):3214-3221.

22. Erickson HK, Widdison WC, Mayo MF, et al. Tumor delivery and in vivo processing of disulfide-linked and thioether-linked antibodymaytansinoid conjugates. Bioconjug Chem. 2010;21(1):84-92.

23. Nolting B. Linker technologies for antibody-drug conjugates. Methods Mol Biol. 2013;1045:71-100.

24. Willner D, Trail PA, Hofstead SJ, et al. (6-maleimidocaproyl)hydrazone of doxorubicin: a new derivative for the preparation of immunoconjugates of doxorubicin. Bioconjug Chem. 1993;4(6):521-527.

25. Hamann PR, Hinman LM, Beyer CF, et al. An anti-MUC1 antibodycalicheamicin conjugate for treatment of solid tumors. Choice of linker and overcoming drug resistance. Bioconjug Chem. 2005;16(2):346-353.

26. Zhao RY, Wilhelm SD, Audette C, et al. Synthesis and evaluation of hydrophilic linkers for antibody-maytansinoid conjugates. J Med Chem. 2011;54(10):3606-3623.

27. Doronina SO, Toki BE, Torgov MY, et al. Development of potent monoclonal antibody auristatin conjugates for cancer therapy. Nat Biotechnol. 2003;21(7):778-784.

28. Kellogg BA, Garrett L, Kovtun Y, et al. Disulfide-linked antibodymaytansinoid conjugates: optimization of in vivo activity by varying the steric hindrance at carbon atoms adjacent to the disulfide linkage. Bioconjug Chem. 2011;22(4):717-727.

29. Tassone P, Gozzini A, Goldmacher V, et al. In vitro and in vivo activity of the maytansinoid immunoconjugate huN901-N2'-deacetyl-N2'-(3mercapto-1-oxopropyl)-maytansine against CD56+ multiple myeloma cells. Cancer Res. 2004;64(13):4629-4636.

30. Al-Katib AM, Aboukameel A, Mohammad R, Bissery MC, ZuanyAmorim C. Superior antitumor activity of SAR3419 to rituximab in xenograft models for non-Hodgkin's lymphoma. Clin Cancer Res. 2009;15(12):4038-4045.

31. Sanderson RJ, Hering MA, James SF, et al. In vivo drug-linker stability of an anti-CD30 dipeptide-linked auristatin immunoconjugate. Clin Cancer Res. 2005;11(2 Pt 1):843-852.

32. Doronina SO, Mendelsohn BA, Bovee TD, et al. Enhanced activity of monomethylauristatin $\mathrm{F}$ through monoclonal antibody delivery: effects of linker technology on efficacy and toxicity. Bioconjug Chem. 2006;17(1):114-124.

33. Petrylak D, Smith D, Appleman L, et al. A phase II trial of prostatespecific membrane antigen antibody drug conjugate in taxane-refractory metastatic castration-resistant prostate cancer. J Clin Oncol. 2014; 32(5s):5023.

34. Wang X, Ma D, Olson WC, Heston WD. In vitro and in vivo responses of advanced prostate tumors to PSMA ADC, an auristatin-conjugated antibody to prostate-specific membrane antigen. Mol Cancer Ther. 2011;10(9):1728-1739.

35. Vaklavas C, Forero A. Management of metastatic breast cancer with second-generation antibody-drug conjugates: focus on glembatumumab vedotin (CDX-011, CR011-vcMMAE). BioDrugs. 2014;28(3): 253-263.

36. Doronina SO, Bovee TD, Meyer DW, et al. Novel peptide linkers for highly potent antibody-auristatin conjugate. Bioconjug Chem. 2008;19(10):1960-1963.

37. Polson AG, Calemine-Fenaux J, Chan P, et al. Antibody-drug conjugates for the treatment of non-Hodgkin's lymphoma: target and linker-drug selection. Cancer Res. 2009;69(6):2358-2364.

38. Lewis Phillips GD, Li G, Dugger DL, et al. Targeting HER2-positive breast cancer with trastuzumab-DM1, an antibody-cytotoxic drug conjugate. Cancer Res. 2008;68(22):9280-9290.

39. Bross PF, Beitz J, Chen G, et al. Approval summary: gemtuzumab ozogamicin in relapsed acute myeloid leukemia. Clin Cancer Res. 2001;7(6):1490-1496.

40. Sievers EL, Larson RA, Stadtmauer EA, et al. Efficacy and safety of gemtuzumab ozogamicin in patients with CD33-positive acute myeloid leukemia in first relapse. J Clin Oncol. 2001;19(13):3244-3254.
41. Petersdorf SH, Kopecky KJ, Slovak M, et al. A phase 3 study of gemtuzumab ozogamicin during induction and postconsolidation therapy in younger patients with acute myeloid leukemia. Blood. 2013;121(24):4854-4860.

42. Amiri-Kordestani L, Blumenthal GM, Xu QC, et al. FDA approval: ado-trastuzumab emtansine for the treatment of patients with HER2positive metastatic breast cancer. Clin Cancer Res. Epub May 30, 2014.

43. de Claro RA, McGinn K, Kwitkowski V, et al. US food and drug administration approval summary: brentuximab vedotin for the treatment of relapsed Hodgkin lymphoma or relapsed systemic anaplastic large-cell lymphoma. Clin Cancer Res. 2012;18(21):5845-5849.

44. Hudis CA. Trastuzumab: mechanism of action and use in clinical practice. N Engl J Med. 2007;357(1):39-51.

45. Slamon DJ, Leyland-Jones B, Shak S, et al. Use of chemotherapy plus a monoclonal antibody against HER2 for metastatic breast cancer that overexpressed HER2. N Engl J Med. 2001;344(11):783-792.

46. Baselga J, Norton L, Albanell J, Kim YM, Mendelsohn J. Recombinant humanized anti-HER2 antibody (herceptin) enhances the antitumor activity of paclitaxel and doxorubicin against HER2/neu overexpressing human breast cancer xenografts. Cancer Res. 1998;58(13): 2825-2831.

47. Press MF, Cordon-Cardo C, Slamon DJ. Expression of the HER-2/neu proto-oncogene in normal human adult and fetal tissues. Oncogene. 1990;5(7):953-962.

48. Sjogren S, Inganas M, Lindgren A, Holmberg L, Bergh J. Prognostic and predictive value of c-erbB-2 overexpression in primary breast cancer, alone and in combination with other prognostic markers. J Clin Oncol. 1998;16(2):462-469.

49. Carter P, Smith L, Ryan M. Identification and validation of cell surface antigens for antibody targeting in oncology. Endocr Relat Cancer. 2004;11(4):659-687.

50. Ohlschlegel C, Zahel K, Kradolfer D, Hell M, Jochum W. HER2 genetic heterogeneity in breast carcinoma. J Clin Pathol. 2011;64(12): 1112-1116.

51. Yang YL, Fan Y, Lang RG, et al. Genetic heterogeneity of HER2 in breast cancer: Impact on HER2 testing and its clinicopathologic significance. Breast Cancer Res Treat. 2012;134(3):1095-1102.

52. Austin CD, De Maziere AM, Pisacane PI, et al. Endocytosis and sorting of ErbB2 and the site of action of cancer therapeutics trastuzumab and geldanamycin. Mol Biol Cell. 2004;15(12):5268-5282.

53. Krop IE, Beeram M, Modi S, et al. Phase I study of trastuzumab-DM1, an HER2 antibody-drug conjugate, given every 3 weeks to patients with HER2-positive metastatic breast cancer. J Clin Oncol. 2010;28(16): 2698-2704.

54. Verma S, Miles D, Gianni L, et al. Trastuzumab emtansine for HER2-positive advanced breast cancer. $N$ Engl J Med. 2012;367(19): 1783-1791.

55. Baselga J, Cortes J, Kim SB, et al. Pertuzumab plus trastuzumab plus docetaxel for metastatic breast cancer. $N$ Engl J Med. 2012;366(2): 109-119.

56. Hoffman-La Roche. A Study of Trastuzumab Emtansine (T-DM1) Plus Pertuzumab/Pertuzumab Placebo Versus Trastuzumab Plus a Taxane in Patients With Metastatic Breast Cancer (MARIANNE). Available from: http://clinicaltrials.gov/show/NCT01120184. NLM identifier: NCT01120184. Accessed September 5, 2014.

57. Hoffman-La Roche. A Study of Trastuzumab Emtansine in Comparison With Treatment of Physician's Choice in Patients With HER2Positive Breast Cancer Who Have Received At Least Two Prior Regimens of HER2-Directed Therapy (TH3RESA). Available from: http://clinicaltrials.gov/ct2/show/NCT01419197. NLM identifier: NCT0141919. Accessed September 5, 2014.

58. Dana-Farber Cancer Institute. T-DM1 vs Paclitaxel/Trastuzumab for Breast (ATEMPT Trial). Available from: http://clinicaltrials.gov/ ct2/show/NCT01853748. NLM identifier: NCT01853748. Accessed September 5, 2014. 
59. Hoffmann-La Roche. A Study of Kadcyla (Trastuzumab Emtansine) Plus Perjeta (Pertuzumab) Following Anthracyclines in Comparison With Herceptin (Trastuzumab) Plus Perjeta and a Taxane Following Anthracyclines As Adjuvant Therapy in Patients With Operable HER2Positive Primary Breast Cancer. Available from: http://clinicaltrials.gov/ ct2/show/NCT01966471. NLM identifier: NCT01966471. Accessed September 5, 2014.

60. Hoffmann-La Roche. A Study of Trastuzumab Emtansine Versus Trastuzumab as Adjuvant Therapy in Patients With HER2-Positive Breast Cancer Who Have Residual Tumor in the Breast or Axillary Lymph Nodes Following Preoperative Therapy (KATHERINE). Available from: http:/clinicaltrials.gov/ct2/show/NCT01772472. NLM identifier: NCT01772472. Accessed September 5, 2014.

61. West German Study Group. A Prospective, Randomized Multicenter, Open-Label Comparison of Preoperative Trastuzumab Emtansine (T-DM1) With or Without Standard Endocrine Therapy Vs Trastuzumab With Standard Endocrine Therapy Given for Twelve Weeks in Patients With Operable HER2+/HR+ Breast Cancer Within the ADAPT Protocol. (ADAPT; T-DM1). Available from: http://clinicaltrials.gov/ct2/show/ NCT01745965. NLM identifier: NCT01745965. Accessed September 5, 2014.

62. Genentech. A Study of Trastuzumab Emtansine, Paclitaxel, and Pertuzumab in Patients With HER2-Positive, Locally Advanced or Metastatic Breast Cancer. Available from: http://clinicaltrials.gov/ ct2/show/NCT00951665. NLM identifier: NCT00951665. Accessed September 5, 2014.

63. Swiss Group for Clinical Cancer Research. Trastuzumab and Pertuzumab Followed by T-DM1 in MBC. Available from: http://clinicaltrials. gov/ct2/show/NCT01835236. NLM identifier: NCT01835236. Accessed September 5, 2014.

64. Dieras V. A phase Ib/II trial of trastuzumab-DM1 with pertuzumab for patients with HER2-positive, locally advanced or metastatic breast cancer: interim efficacy and safety results. Poster presented at: 33rd Annual San Antonio Breast Cancer Symposium; December 2010.

65. Barok M, Tanner M, Koninki K, Isola J. Trastuzumab-DM1 is highly effective in preclinical models of HER2-positive gastric cancer. Cancer Lett. 2011;306(2):171-179.

66. Hoffmann-La Roche. A Study of Trastuzumab Emtansine Versus Taxane in Patients With Advanced Gastric Cancer. Available from: http://clinicaltrials.gov/ct2/show/NCT01641939. NLM identifier: NCT01641939. Accessed September 5, 2014.

67. Horie R, Watanabe T. CD30: Expression and function in health and disease. Semin Immunol. 1998;10(6):457-470.

68. Falini B, Pileri S, Pizzolo G, et al. CD30 (ki-1) molecule: a new cytokine receptor of the tumor necrosis factor receptor superfamily as a tool for diagnosis and immunotherapy. Blood. 1995;85(1):1-14.

69. Ansell SM, Horwitz SM, Engert A, et al. Phase I/II study of an antiCD30 monoclonal antibody (MDX-060) in Hodgkin's lymphoma and anaplastic large-cell lymphoma. J Clin Oncol. 2007;25(19): 2764-2769.

70. Forero-Torres A, Leonard JP, Younes A, et al. A phase II study of SGN-30 (anti-CD30 mAb) in Hodgkin lymphoma or systemic anaplastic large cell lymphoma. Br J Haematol. 2009;146(2):171-179.

71. Francisco JA, Cerveny CG, Meyer DL, et al. cAC10-vcMMAE, an anti-CD30-monomethyl auristatin E conjugate with potent and selective antitumor activity. Blood. 2003;102(4):1458-1465.

72. Younes A, Bartlett NL, Leonard JP, et al. Brentuximab vedotin (SGN-35) for relapsed CD30-positive lymphomas. $N$ Engl J Med. 2010;363(19):1812-1821.

73. Fanale MA, Forero-Torres A, Rosenblatt JD, et al. A phase I weekly dosing study of brentuximab vedotin in patients with relapsed/refractory CD30-positive hematologic malignancies. Clin Cancer Res. 2012;18(1): 248-255.

74. Younes A, Gopal AK, Smith SE, et al. Results of a pivotal phase II study of brentuximab vedotin for patients with relapsed or refractory Hodgkin's lymphoma. J Clin Oncol. 2012;30(18):2183-2189.
75. Pro B, Advani R, Brice P, et al. Brentuximab vedotin (SGN-35) in patients with relapsed or refractory systemic anaplastic large-cell lymphoma: results of a phase II study. J Clin Oncol. 2012;30(18):2190-2196.

76. Chen R, Palmer JM, Thomas SH, et al. Brentuximab vedotin enables successful reduced-intensity allogeneic hematopoietic cell transplantation in patients with relapsed or refractory Hodgkin lymphoma. Blood. 2012;119(26):6379-6381.

77. Gopal AK, Ramchandren R, O'Connor OA, et al. Safety and efficacy of brentuximab vedotin for Hodgkin lymphoma recurring after allogeneic stem cell transplantation. Blood. 2012;120(3):560-568.

78. Seattle Genetics, Inc. A Phase 3 Study of Brentuximab Vedotin (SGN-35) in Patients at High Risk of Residual Hodgkin Lymphoma Following Stem Cell Transplant (The AETHERA Trial). Available from: http://clinicaltrials.gov/show/NCT01100502. NLM identifier: NCT01100502. Accessed September 5, 2014.

79. Millennium Pharmaceuticals, Inc. Phase 3 Frontline Therapy Trial in Patients With Advanced Classical Hodgkin Lymphoma. Available from: http://clinicaltrials.gov/show/NCT01712490. NLM identifier: NCT01712490. Accessed September 5, 2014.

80. Silver DA, Pellicer I, Fair WR, Heston WD, Cordon-Cardo C. Prostatespecific membrane antigen expression in normal and malignant human tissues. Clin Cancer Res. 1997;3(1):81-85.

81. Sokoloff RL, Norton KC, Gasior CL, Marker KM, Grauer LS. A dual-monoclonal sandwich assay for prostate-specific membrane antigen: levels in tissues, seminal fluid and urine. Prostate. 2000;43(2): $150-157$.

82. Ananias HJ, van den Heuvel MC, Helfrich W, de Jong IJ. Expression of the gastrin-releasing peptide receptor, the prostate stem cell antigen and the prostate-specific membrane antigen in lymph node and bone metastases of prostate cancer. Prostate. 2009;69(10):1101-1108.

83. Wright GL Jr, Grob BM, Haley C, et al. Upregulation of prostatespecific membrane antigen after androgen-deprivation therapy. Urology. 1996;48(2):326-334.

84. Evans MJ, Smith-Jones PM, Wongvipat J, et al. Noninvasive measurement of androgen receptor signaling with a positron-emitting radiopharmaceutical that targets prostate-specific membrane antigen. Proc Natl Acad Sci U S A. 2011;108(23):9578-9582.

85. Miyamoto DT, Lee RJ, Stott SL, et al. Androgen receptor signaling in circulating tumor cells as a marker of hormonally responsive prostate cancer. Cancer Discov. 2012;2(11):995-1003.

86. Haffner MC, Kronberger IE, Ross JS, et al. Prostate-specific membrane antigen expression in the neovasculature of gastric and colorectal cancers. Hum Pathol. 2009;40(12):1754-1761.

87. Liu H, Moy P, Kim S, et al. Monoclonal antibodies to the extracellular domain of prostate-specific membrane antigen also react with tumor vascular endothelium. Cancer Res. 1997;57(17):3629-3634.

88. Milowsky MI, Nanus DM, Kostakoglu L, Vallabhajosula S, Goldsmith SJ, Bander NH. Phase I trial of yttrium-90-labeled antiprostate-specific membrane antigen monoclonal antibody J591 for androgen-independent prostate cancer. J Clin Oncol. 2004;22(13): 2522-2531.

89. Bander NH, Milowsky MI, Nanus DM, Kostakoglu L, Vallabhajosula S, Goldsmith SJ. Phase I trial of 177lutetium-labeled J591, a monoclonal antibody to prostate-specific membrane antigen, in patients with androgen-independent prostate cancer. J Clin Oncol. 2005;23(21): 4591-4601.

90. Tagawa ST, Beltran H, Vallabhajosula S, et al. Anti-prostate-specific membrane antigen-based radioimmunotherapy for prostate cancer. Cancer. 2010;116(Suppl 4):1075-1083.

91. Tagawa ST, Milowsky MI, Morris M, et al. Phase II study of lutetium177 labeled anti-prostate-specific membrane antigen (PSMA) monoclonal antibody J591 for metastatic castration-resistant prostate cancer. Clin Cancer Res. 2013;19(18):5182-5191.

92. Osborne JR, Akhtar NH, Vallabhajosula S, Anand A, Deh K, Tagawa ST. Prostate-specific membrane antigen-based imaging. Urol Oncol. 2013;31(2):144-154. 
93. Henry MD, Wen S, Silva MD, Chandra S, Milton M, Worland PJ. A prostate-specific membrane antigen-targeted monoclonal antibodychemotherapeutic conjugate designed for the treatment of prostate cancer. Cancer Res. 2004;64(21):7995-8001.

94. Galsky MD, Eisenberger M, Moore-Cooper S, et al. Phase I trial of the prostate-specific membrane antigen-directed immunoconjugate MLN2704 in patients with progressive metastatic castration-resistant prostate cancer. J Clin Oncol. 2008;26(13):2147-2154.
95. Milowsky MI, Galsky M, George DJ, et al. Phase I/II trial of the prostate-specific membrane antigen (PSMA)-targeted immunoconjugate MLN2704 in patients (pts) with progressive metastatic castration resistant prostate cancer (CRPC). J Clin Oncol (Meeting Abstracts). 2006;24(Suppl 18):4500.

\section{Publish your work in this journal}

OncoTargets and Therapy is an international, peer-reviewed, open access journal focusing on the pathological basis of all cancers, potential targets for therapy and treatment protocols employed to improve the management of cancer patients. The journal also focuses on the impact of management programs and new therapeutic agents and protocols on

\section{Dovepress}

patient perspectives such as quality of life, adherence and satisfaction The manuscript management system is completely online and includes a very quick and fair peer-review system, which is all easy to use. Visit http://www.dovepress.com/testimonials.php to read real quotes from published authors. 